\title{
POTASSIUM EFFECTS ON T WAVE INVERSION IN MYOCARDIAL INFARCTION AND PREPONDERANCE OF A VENTRICLE
}

\author{
BY \\ E. P. SHARPEY-SCHAFER \\ From the Department of Medicine, British Postgraduate Medical School, London \\ Received December 5, 1942
}

The action of potassium on the normal $\mathrm{T}$ wave of the electrocardiogram has been established in several species. Wiggers (1930) showed that there was a rise in the normal upright $\mathrm{T}$ wave after injection of potassium salts into dogs. Similar results have been found in man after large doses of potassium salts by mouth and intravenously (Thompson, 1939, a \& b ; and Keith, Osterberg, \& Burchell, 1942). The possibility that changes produced by raising the serum potassium might throw some light on low voltage electrocardiograms led to the investigation of cases of thyroid deficiency (Sharpey-Schafer, 1943). In cases showing $T$ wave inversion in all standard leads, it was found that potassium caused the $T$ waves to become upright. It became necessary, therefore, to investigate the effect of potassium on other forms of $\mathrm{T}$ inversion. This paper reports the results obtained in cases with myocardial infarction and cases with preponderance of the left or right ventricle.

Methods. -15 to $20 \mathrm{~g}$. of an equal mixture of potassium chloride and potassium citrate dissolved in about 250 c.c. of water were given by mouth or by stomach tube. Cardiograms were taken before, one to one and a half, and two to two and a half hours after. Chest leads used were IV R, LP-R, RP-R (Wood and Selzer, 1939). Blood samples were taken at the same time as the cardiograms, and serum potassium was estimated by a modification of the method of Kramer and Tisdall (1921). A few subjects showed little or no change in the serum potassium and cardiogram after these doses of salt, and there was considerable individual variation in response, as has been noted by Keith, Osterberg, and Burchell (1942). Successful observations were made in the following: 4 cases with T III pattern myocardial infarction, 4 with $T$ I pattern myocardial infarction, 9 with $T$ inversion due to left ventricular preponderance, and 4 with $T$ inversion due to right ventricular preponderance.

\section{RESULTS}

Throughout each group the results were the same.

T III pattern myocardial infarction.-T III became more inverted and T I more upright (Fig. 1). The three chest leads, as expected, became more upright.

TI pattern myocardial infarction.-T I became more inverted and T III more upright (Fig. 3). TIV followed T I, and S-T elevation was often accentuated. The original pattern of each case was not, however, changed.

Left ventricular preponderance with $T$ I and TIV inverted.-In comparison with T I pattern cardiograms the effect of potassium was exactly opposite, TI and T IV becoming upright (Fig. 4).

Left ventricular preponderance, concordant type.-In this type of case, usually aortic stenosis or hypertensive heart disease, $T$ waves are apparently inverted in all standard leads, and QRS may show no axis shift. The effect of potassium is to throw all $\mathrm{T}$ waves sharply 


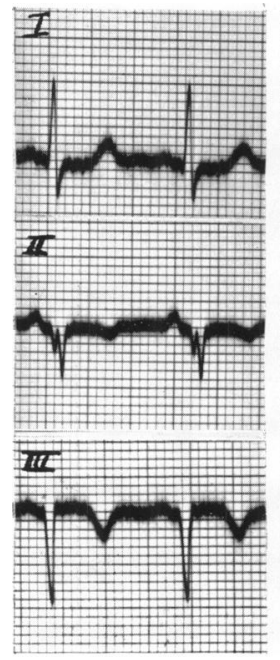

A Fig. 1.

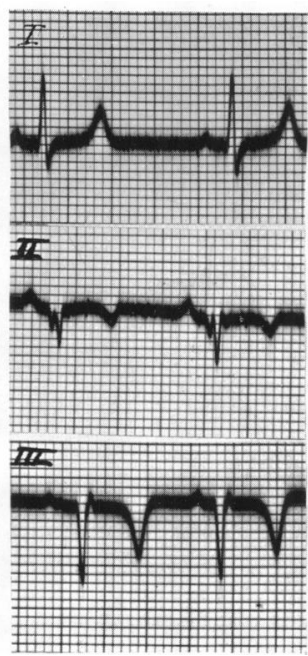

B

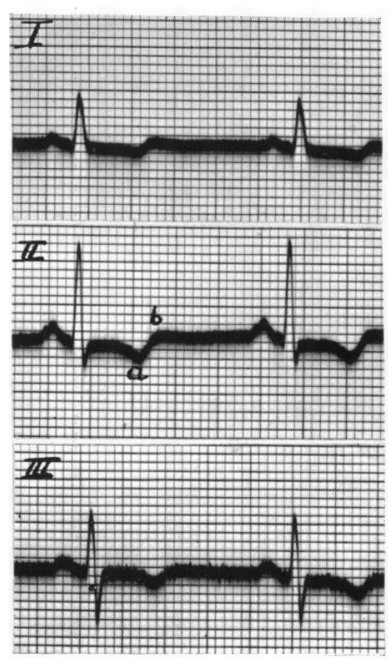

A

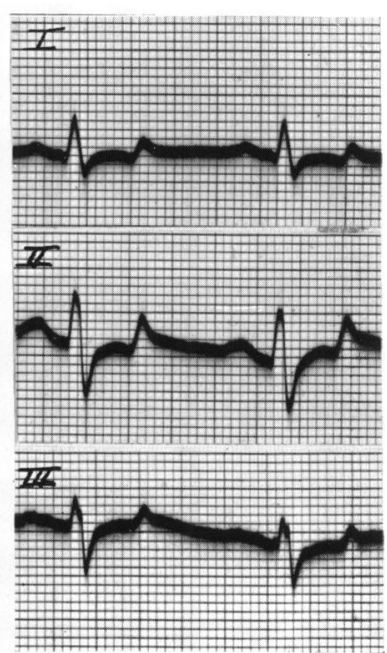

FIG. 2.

upright, while the upward-curved S-T depression remains or may even be accentuated (Fig. 2).

Right ventricular preponderance.-Three cases of chronic cor pulmonale, due to emphysema, were investigated. Results were similar to those found in left preponderance. $T$ inversion, best seen in the chest leads, became upright after potassium (Fig. 5). A similar striking result was seen in a case of acute cor pulmonale due to a packed pulmonary embolism (to be published elsewhere).

Other effects of potassium.-Flattening of the $\mathrm{P}$ waves and widening of QRS occurred when the rise of serum potassium was great. Similar changes with the same degree of serum potassium rise have been reported in dogs by Hoff, Smith, and Winkler (1941). No patient with myocardial infarction complained of chest pain after potassium, and no patient showed rhythm changes.

\section{Discussion}

The results of this investigation indicate that raising the serum potassium may prove a valuable method in the practical analysis of the electrocardiogram. Curves are often seen that are difficult to interpret without serial observation over long periods, while giving potassium salts by mouth offers the possibility of interpretation within a few hours. The safety of the procedure needs some discussion. Hoff, Smith, and Winkler (1941) have shown that death may result in dogs when the serum potassium is trebled, and from levels observed in cases of uræmia similar results might be expected in man. In our series the greatest rise of serum potassium was from $21 \mathrm{mg}$. to $38 \mathrm{mg}$. per 100 c.c. of serum. Several of the subjects with hypertensive heart disease had impairment of renal function, while several others had congestive heart failure. It might be wise, however, to exercise caution in patients suspected of having myocardial infarction, since Katz and Linder (1938) have shown that potassium diminishes coronary flow. $10 \mathrm{~g}$. or less of potassium salts might be given to such patients as a preliminary trial to determine individual response. Both Thompson (1939b) and Keith, Osterberg, and Burchell (1942) thought that cardiographic changes did not follow strictly 

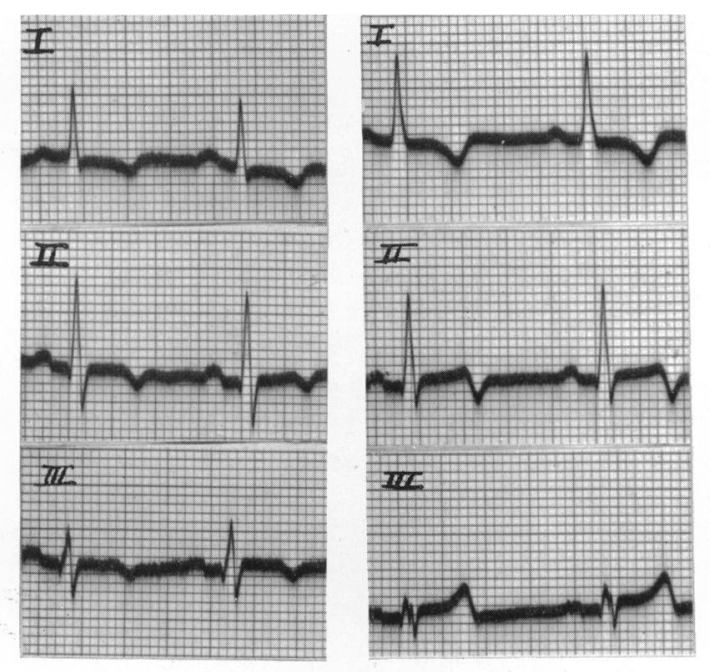

the rise in serum potassium. Consideration of their published figures and our own data suggest that the evidence is not sufficient to warrant an opinion. In general, the opinion of Hoff, Smith, and Winkler, that the cardiogram follows the serum potassium, seems correct. The theoretical aspect presents great difficulties. Fenn (1940), reviewing the physiological role of potassium, has stressed our ignorance of electrolyte exchange. Joseph, Cohn, and Greenberg (1939), using radioactive potassium, showed that most of the ingested potassium was taken up by the liver, and that the rise in extracellular fluids preceded by some hours the rise in cells. It is possible that cardiographic changes produced by these doses of potassium salts result solely from electrolyte changes in the extracellular fluids or in the general " conducting medium" to the periphery of which leads are attached. Yet potassium presumably affects the heart itself, as numerous workers since Blake (1839) have shown that standstill and death result from excess. Careful inspection of our results reveals no evidence that potassium produces specific changes in the normal or abnormal cardiogram, as, for example, does digitalis. The effect, so far as $\mathrm{S}-\mathrm{T}$ interval and $\mathrm{T}$ wave are concerned, appears to be an accentuation of deflections that are already present. Thus S-T deviation rather than deepen- 

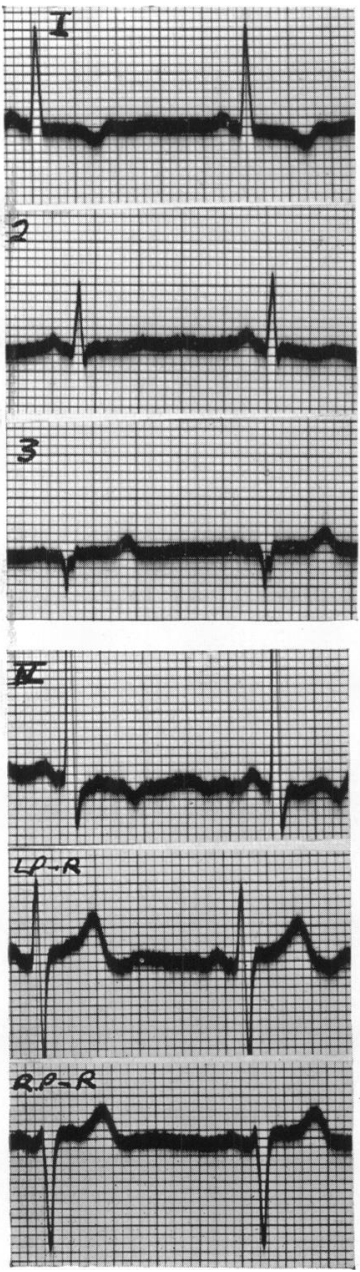

A
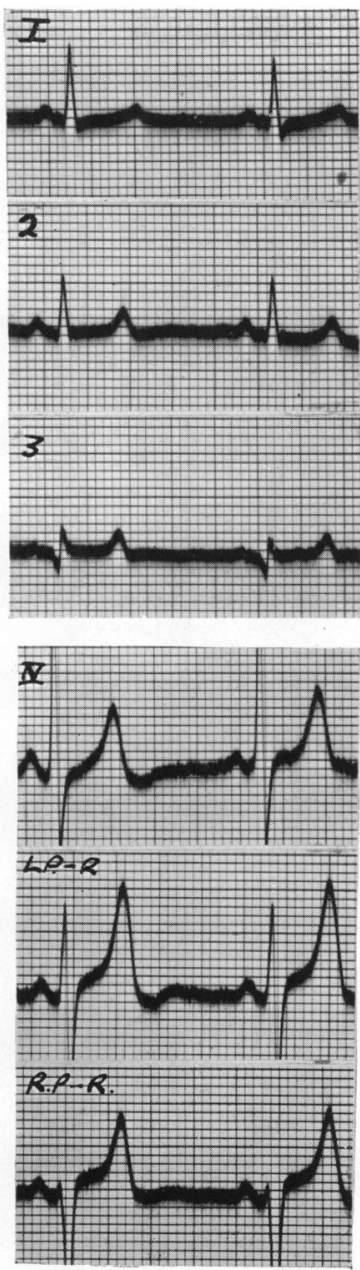

B

Fig. 4.
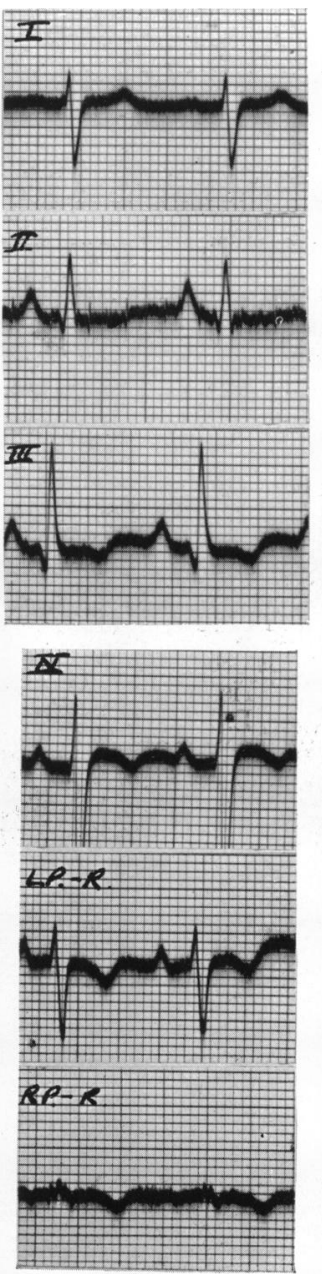

A
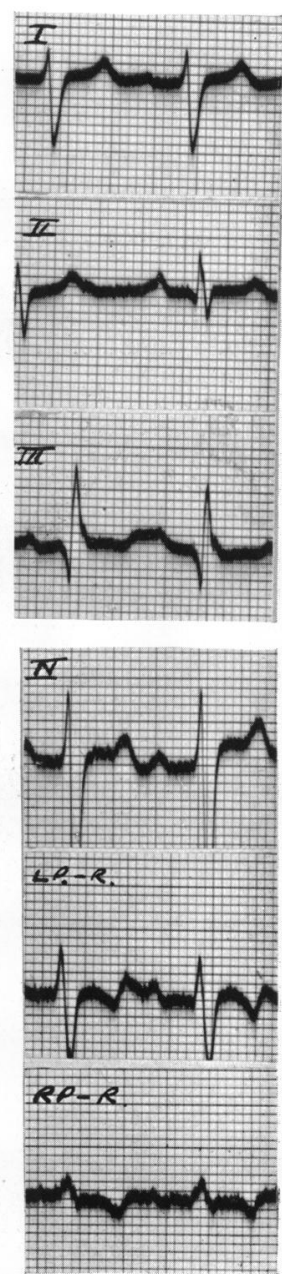

B

FIG. 5.

FIG. 4.-Left ventricular preponderance. Hypertensive heart disease.

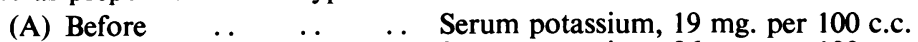

(B) 1 hour after $\quad$. $\quad$. $\quad$ Serum potassium, 26 mg. per 100 c.c.

Fig. 5.-Right ventricular preponderance. Chronic cor pulmonale from emphysema.

(A) Before $\quad . . \quad \ldots \quad$.. $\quad$ Serum potassium, $20 \mathrm{mg}$. per 100 c.c.

(B) $2 \frac{1}{4}$ hours after $\quad \ldots \quad \ldots$ Serum potassium, $23 \mathrm{mg}$. per 100 c.c.

ing of the $\mathrm{T}$ wave would be expected in cases of myocardial infarction, were potassium to cause further acute ischæmia of the myocardium. The theory of the normal and abnormal deflection of retreat in the human cardiogram is still obscure. Interpretation is therefore necessarily empirical. The effect of potassium on simple systems consisting of muscle strips in a conducting medium, such as those described by Craib (1930) has not apparently been studied. However, the results obtained on " $\mathrm{T}$ inversion" in preponderance of a ventricle are of some theoretical interest. Most workers would agree that this inversion is a fundamentally different mechanism from that seen in disease of the coronary artery. The appearance of an upright $\mathrm{T}$ wave after potassium suggests that inversion in preponderance of a ventricle may be an S-T rather than a $T$ wave change and that in Fig. 2, lead II, the point " $b$ " rather than " $a$ " is the apex of the $T$ wave. In some curves this is substantiated by $Q-T$ measurements, but, in view of QRS widening and other factors after potassium, considerably more evidence is required before such measurements can be analysed. 
$\mathrm{T}$ wave inversion due to myocardial infarction is further inverted by raising the serum potassium, while $\mathrm{T}$ wave inversion due to preponderance of a ventricle becomes upright after potassium.

The method is useful in analysis of difficult electrocardiograms. It is suggested that $\mathrm{T}$ inversion in ventricular preponderance is an $\mathrm{S}-\mathrm{T}$ change, not a $\mathrm{T}$ wave change.

Serum potassium was estimated in the School laboratories (Director, Dr. E. J. King). My thanks are due to the Chief Medical Officer, L.C.C., for permission to publish the clinical material.

\section{REFERENCES}

Blake, J. (1839). Edin. med. J., 51, 330.

Craib, W. H. (1930). Medical Research Council Report No. 147.

Fenn, W. O. (1940). Physiol. Rev., 20, 377.

Hoff, H. E., Smith, P. K., and Winkler, A. W. (1941). J. clin. Invest., 20, 607.

Joseph, M., Cohn, W. E., and Greenberg, D. M. (1939). J. biol. Chem., 128, 673.

Katz, L. N., and Linder, E. (1938). Amer. J. Physiol., 124, 155.

Keith, N. M., Osterberg, A. E., and Burchell, H. B. (1942). Ann. intern. Med., 16, 879.

Kramer, B., and Tisdall, F. F. (1921). J. biol. Chem., 46, 339.

Sharpey-Schafer, E. P. (1943). Brit. Heart J., 5, 85 .

Thompson, W. A. R. (1939). a. Lancet, 1, 808.

(1939). b. Brit. Heart J., 1, 269.

Wiggers, C. J. (1930). Amer. J. Physiol., 93, 197.

Wood, P., and Selzer, A. (1939). Brit. Heart J., 1, 29. 